\title{
Relatos perdidos. \\ Dictadura cívico militar, Guerra de Malvinas y transmisión intergeneracional. ${ }^{1}$
}

\section{Lost stories. \\ Civic-military dictatorship, War of Malvinas and intergenerational transmission.}

\author{
Lucia Briguet $^{2}$
}

"Cuando la memoria de una serie de hechos ya no tiene como soporte el grupo- ese mismo grupo que estuvo implicado o que sufrió las consecuencias, que asistió o recibió un relato vivo de los primeros actores y espectadores-, cuando se dispersa en algunos espiritus individuales, perdidos en sociedades nuevas a las que esos hechos ya no interesan, porque les son decididamente exteriores, entonces el unico modo de salvar tales recuerdos es fijarlos por escrito en una narración ordenada ya que, si las palabras y los pensamientos mueren, los escritos permanecen."

(Halbwachs, La memoria colectiva)

\section{Resumen}

Este texto se propone explorar los efectos de la dictadura cívico militar ocurrida en Argentina entre 1976 y 1983 desde la perspectiva de la transmisión intergeneracional de la memoria a través de la focalización en un acontecimiento en particular: la Guerra de Malvinas. A partir de los postulados de Hassoun (1994) sobre los efectos de las conmociones sociales en diferentes generaciones y las aproximaciones de Feierstein (2012) sobre la dictadura cívico militar entendida como un genocidio, nuestro objetivo será ahondar y ampliar el debate, tanto clínico como sociológico, sobre las consecuencias en grupos afectados directa e indirectamente por la Guerra de Malvinas. En la primera parte desplegamos la indagación del tema y los conceptos desde los cuales lo abordamos y sobre el final consideramos relatos de hijos de ex combatientes de la guerra de Malvinas planteando algunas conclusiones que se desprenden de cotejar nuestra posición teórica con la información recogida. El objetivo es aproximarnos a algunas hipótesis que nos permitan pensar en posibles vías de elaboración para ese tipo de sucesos.

\section{Palabras claves}

Guerra de Malvinas - dictadura civico-militar - transmision intergeneracional - memorias - excombatientes

\section{Abstract}

This text aims to explore the effects of the civic-military dictatorship occured in

\footnotetext{
${ }^{1}$ El presente artículo fue reescrito sobre la base del Trabajo Final Integrador de la Carrera de Especialización en Psicología Clínica, Institucional y Comunitaria "Vicisitudes en la transmisión entre generaciones afectadas por la violencia de la última dictadura militar Argentina. El caso particular de los sobrevivientes de la guerra de Malvinas" del que soy autora y que fuera dirigido por el Psicólogo Iván Fina.

${ }^{2}$ Psicóloga, Especialista en Psicología Clínica, Institucional y Comunitaria (Rosario, Argentina). Correo electrónico: luciabriguet@gmail.com.
} 
Argentina between 1976 and 1983 from the perspective of the intergenerational transmission of the memory focusing mainly in an event: the War of Malvinas. From the postulates of Hassoun (1994) on the effects of the social shocks in different generations and the approximations of Feierstein (2012) on the civic-military dictatorship, understood as a genocide. Our goal will be to go deeply and to extend debate, both clinical and sociological, on the consequences that the war of Malvinas had either directly or inderectly on affected groups. In the first part we open the investigation of the topic and introduce the concepts that we deploy in it, and in the end, we consider the War of Malvinas ex-soldiers children drawing some conclusions that become detached of comparing our theoretical position with the information collected. The aim is to come closer to some hypothesis that could allow us to think about possible ways of elaboration of this type of events.

\section{Keywords}

War of Malvinas - civic-military dictatorship - intergenerational transmission - memories - exsoldiers

\section{Introducción}

En este texto exploraremos el tema de las vicisitudes en la transmisión entre generaciones afectadas por la dictadura cívico militar ocurrida en Argentina entre 1976 y 1983. Entendemos que tanto la generación que vivió en ese momento como la que nació y creció luego de 1983 están marcadas por la dictadura de distintos modos. Para abordar la cuestión elegimos un acontecimiento en particular, que fue parte histórica de ese proceso, y que es la llamada guerra de Malvinas, centrándonos en el grupo que participó del mismo. Partimos de la idea de que lo experimentado por una generación impone un trabajo particular a la siguiente y de que parte de la generación que fue joven durante la última dictadura cívico militar se caracteriza, entre otras cosas, por el hecho de ser sobreviviente. Así es que interrogaremos qué ocurre cuando la transmisión está fuertemente marcada por experiencias que son particularmente difíciles de elaborar.

Las preocupaciones que guiaron este trabajo pueden expresarse a través de los siguientes interrogantes: ¿Qué construcciones pudieron hacerse de la experiencia del pasado? ¿Qué exigencias de trabajo impuso a parte de la generación que nació y creció posdictadura la condición de los padres? ¿Qué modalidades de sufrimiento? ¿Cómo la trama social influyó en la transmisión de lo no transmisible de la experiencia?

Trabajamos desde una lógica cualitativa a través del análisis de material teórico relacionado con el tema y de una muestra compuesta por material extraído de entrevistas personales a hijos ${ }^{3}$ de soldados que participaron en la guerra de Malvinas. Las entrevistas fueron abiertas porque intentamos captar aquello que los entrevistados decían espontáneamente dando oportunidad a que aparecieran puntos inéditos.

Consideramos que aproximarnos a la guerra de Malvinas enmarcándola en el plano más general de la dictadura cívico-militar y poniendo el eje en la transmisión intergeneracional es de suma importancia tanto desde una perspectiva clínica como desde un punto de vista histórico y político porque condensa problemáticas cruciales a investigar en un país como el nuestro, que sufrió repetidos procesos de violencia estatal derivados de Golpes de Estado. A su vez, que hayan pasado más de treinta años de esos acontecimientos nos permite contar con un copioso e interesante conjunto de investigaciones de gran ayuda para

\footnotetext{
${ }^{3}$ Por razones de confidencialidad no mencionamos los nombres ni las características de los entrevistados, solo aclararemos que las edades oscilaron entre 19 y 28 años.
} 
aproximarnos al tema situado. Reflexionaremos, entonces, acerca de aquello que propicia u obstaculiza cierto trabajo de elaboración a través de los cuales los hombres fueron y son capaces de reinventar sus historias.

En el libro Los contrabandistas de la memoria, el psicoanalista Hassoun (1994) afirma que lo que define a los seres humanos es el hecho de ser portadores y pasadores de historias. Se trata de "un saber sobre la muerte y la genealogía que dicta la necesidad de que un mínimo de continuidad sea asegurada" (p. 15). Los hombres transmiten a sus descendientes experiencias del pasado que cada generación actualiza de acuerdo a las vicisitudes de sus experiencias y deseos. Pero, nos advierte el autor, también pueden darse cortes y rupturas en los procesos de transmisión. A partir de su trabajo clínico con personas de diferentes comunidades de Europa afirma que cuando acontecimientos históricos conmueven las historias familiares, se pueden dar interrupciones en la transmisión de cuestiones que quedan en estado de duelos imposibles de hacer, secretos y otros fenómenos que generan sufrimiento e impiden construir una novela familiar a partir de la cual proyectar un futuro.

Por otro lado, en Memorias y representaciones. Sobre la elaboración del genocidio, el sociólogo Feierstein (2012) ubica que la dictadura cívico-militar ocurrida en Argentina entre 1976 y 1983 se propuso eliminar una parte de la identidad nacional argentina a través del asesinato de personas y del ejercicio del terror lo cual, entre otras cosas, fracturó lazos sociales, redujo la movilización social y obturó la posibilidad de transmisión de ciertas memorias del pasado.

Una forma posible de figurarnos posibles vicisitudes en los procesos de transmisión entre diferentes generaciones puede ser imaginarnos el recorrido de la vida de un hombre como el armado de un gran rompecabezas, cuyas primeras piezas suelen ser trasmitidas, donadas, y las otras deben ser encontradas, construidas, inventadas. Las primeras piezas, entonces, serían donadas por los otros primordiales: madres, padres, abuelas, abuelos, tías, tíos, etc. Pero consideremos que la descendencia de generaciones cuyos rompecabezas tienen muchas piezas destruidas recibe algo de eso en la donación, es decir, que hubo destrucción. Supongamos que tampoco tienen anticipación alguna, no saben cuáles son las piezas que no están y cuáles han sido reconstruidas, no cuentan con un manual de explicaciones sobre cómo o qué armar. Sin embargo, cada tanto se encuentran con partes rotas, desaparecidas o en negro que tienen que traducir para poder seguir.

\section{Dictadura: la destrucción del lazo social.}

Para explorar el tema situado necesitaremos ir y venir por lo que podríamos pensar como cierta novela nacional ${ }^{4}$.

La dictadura cívico-militar que derrocó al gobierno constitucional de Estela Martínez de Perón e instaló en su lugar una Junta Militar encabezada por los comandantes de las tres Fuerzas Armadas, significó una catástrofe para el país en general y, en particular, para aquellas personas que han padecido sus efectos directamente. El proceso que se autodenominó de "Reorganización Nacional" se inscribió en la Doctrina de Seguridad Nacional, doctrina que propició el marco ideológico y metodológico para la implementación de dictaduras, también, en otros países de América Latina ${ }^{5}$. Con la excusa de ordenar el caos,

\footnotetext{
${ }^{4}$ Con la expresión "novela nacional" queremos hacer alusión al concepto de novela familiar que Freud S. trabaja en La novela familiar del neurótico (Freud, 1909 [1908]).

5 "La Doctrina de Seguridad Nacional (DSN) fue el nombre que tuvo la estrategia represiva elaborada por los EE.UU. en el marco de la denominada Guerra Fría, es decir, del conflicto Este-Oeste iniciado al finalizar la Segunda Guerra Mundial entre el blo-
} 
fuerzas militares y paramilitares ejercieron represión, autoritarismo, estigmatización y persecución de cualquier ciudadano que fuera sospechado de "subversivo" y crearon así un estado de miedo permanente en toda la sociedad. Desapariciones, detenciones en centros clandestinos, torturas y asesinatos fueron los métodos utilizados para impartir el terror $\mathrm{y}$ generar estados de crisis y conmoción necesarios para lograr una mayor indefensión en el conjunto social y conseguir su fin último que fue profundizar el modelo neoliberal ${ }^{6}$. Todo

que oriental socialista-bajo el control de la Unión de Repúblicas Socialistas Soviéticas, URSS- y el bloque occidental capitalista bajo el poder de los Estados Unidos. Esta doctrina estaba fundamentada en el concepto de «guerra interna» como respuesta al peligro de la «invasión» comunista. En ese sentido se consideraba que, debido a la expansión soviética, la defensa nacional ya no podía ejercerse sólo a partir de los parámetros de una guerra clásica (territorial y de fronteras en el plano militar) sino que la defensa de la «civilización occidental y cristiana» ante la «amenaza marxista» exigía dar la batalla en todos los frentes: en el ámbito de la cultura, la educación, la economía, la política y la sociedad en su conjunto. Esta doctrina concebía al enemigo como una amenaza que no reconocía fronteras geográficas sino básicamente ideológicas y todos los conflictos -internos y externos- eran leídos en la misma clave interpretativa: el peligro de infiltración marxista. Este criterio llevó a diseñar políticas para las distintas regiones del mundo, entre ellas América Latina, que era considerada «el patio trasero» de EE.UU, es decir, como una zona de influencia y control exclusiva del imperio" (Ministerio de Educación de la Nación Argentina, 2010: 105).

${ }^{6}$ Es Naomi Klien (2008) quien postulando la "doctrina del shock" afirma que el shock colectivo es necesario para el establecimiento de shocks económicos. La autora, investigando la dependencia entre neoliberalismo y lo que ella llama "poder del shock", llega a la conclusión de que la táctica central del capitalismo contemporáneo (al que define como un sistema corporativista porque eliminó los límites entre el gobierno y el sector empresarial) es aprovechar o generar estados de shocks para poder imponer reformas económicas y sociales radicales (desregulaciones estatales, privatizaciones, recortes en gastos sociales, etc...). Estas reformas, por su nocividad, en condi- ello ha dejado graves secuelas en el tejido social por el nivel de crueldad de los métodos utilizados y porque fue el mismo Estado (los grupos que se habían apropiado de él) el que ejerció esa crueldad, es decir, aquella función social que debe encargarse de la protección, de velar por el cumplimiento de cierta legalidad en lo social.

Feieirstein (2012) ubica que la dictadura cívico militar buscó destruir y reorganizar relaciones sociales de autonomía y cooperación para generar un tipo de subjetividad que acepte sin resistencias privilegios a pequeños grupos económicos y una mayor desigualdad social. Propone llamar "genocidio" a esa violencia estatal masiva. En palabras del autor:
La caracterización como un genocidio da cuenta de un proyecto global en el cual el ejerci- cio del terrory su difusión en el conjunto social es el elemento constituyente y fundamental de la práctica, no un exceso o derivado peculiar de ésta. Sostener que Argentina sufrió un ge- nocidio implica, entre otras cosas, que existió un proyecto de reorganización social y nacio- nal que buscó la destrucción de las relaciones sociales de autonomía y cooperación y de la identidad de una sociedad, por medio del ani- quilamiento de una fracción relevante (sea por su número o por los efectos de sus prácticas) de dicha sociedad, y del uso del terror producto del aniquilamiento para el establecimiento de nuevas relaciones sociales y modelos identita- rios (Feierstein, 2012: 140).

ciones de calma y tranquilidad serían rechazadas por la mayor parte de la sociedad. En este sentido los casos de Argentina y Chile son paradigmáticos. Klein demuestra con varios ejemplos cómo la confusión y el caos provocado por acontecimientos traumáticos tales como guerras o dictaduras, o aun catástrofes naturales (terremotos, tsunamis) fueron utilizados (o aún recomendados, de manera más o menos explícita) por los partidarios de esta doctrina para viabilizar políticas económicas que de lo contrario no hubiesen sido aceptadas. 
El ejercicio del terror fue la principal práctica social del Proceso de Reorganización $\mathrm{Na}$ cional que tuvo como objetivo no sólo aniquilar a personas y/o grupos, sino desarmar un lazo, demoler determinada identidad del conjunto social. Y esa práctica fue parte de un proyecto durante años planeado. "El proyecto de reorganización social fue construido persistente y pacientemente, si bien articuló como excusa la lucha contra la subversión, ya venía siendo llevado adelante desde mucho antes de la existencia de la organizaciones armadas de izquierda" (Feierstein, 2012: 154). Feierstein, además, señala que actualmente aparecen las consecuencias de toda esa destrucción en una especie de desensibilización que genera fenómenos tales como desconfianza, indiferencia, apoliticidad, nihilismo, etc. y otras tendencias que priorizan el individualismo y la carrera personal (lo que más adelante se verá como "realización simbólica del genocidio").

En Argentina se logró cierto consenso en considerar que la dictadura fue una catástrofe para toda la sociedad recién después de que algunos de los responsables de los crímenes y delitos cometidos fueran juzgados y condenados como fruto de muchos años de luchas de diferentes organizaciones sociales ${ }^{7}$. Como afirma Feierstein (2012), las calificaciones jurídicas ejercen una importante acción en la posibilidad de elaboración colectiva de experiencias traumáticas porque las lógicas del juicio son "potenciales constructoras de conjuntos de representaciones que tienen la capacidad de instalarse como verdades colectivas." (p. 127) 8

\footnotetext{
${ }^{7}$ Ejemplo de esto son las agrupaciones que formaron los familiares de víctimas y desaparecidos: Familiares de Desaparecidos por Cuestiones Políticas; Madres de Plaza de Mayo, Abuelas de Plaza de Mayo, H.I.J.O.S. ${ }^{8} \mathrm{El}$ año 2003 marcó un punto de inflexión en el sentido común colectivo respecto del tema, a partir de que el entonces presidente Néstor Kirchner escuchara los reclamos de las organizaciones sociales mencionadas e impulsara políticas de Estado en materia de Memo-
}

\section{Sobrevivir a la guerra de Malvinas.}

Malvinas significa, entre otras cosas, un hecho particularmente controvertido porque alude a una guerra entre la República Argentina y el Reino Unido que tuvo lugar en las Islas Malvinas en el año 1982. Las islas Malvinas pertenecen a la plataforma continental Argentina pero desde el año 1833 fueron tomadas y ocupadas por Reino Unido. Desde aquel año el archipiélago se encuentra administrado por Inglaterra pero Argentina reclama una soberanía que le corresponde por razones geográficas (la islas forman parte de su plataforma continental), por razones históricas (fue "territorio heredado" de España a partir de la Revolución de Mayo de 1810 y la Declaración de la Independencia de 1816) y por razones diplomáticas (Argentina reclama sus derechos de soberanía desde 1833) (2014, Ministerio de Educación). Entonces, el reclamo por la soberanía argentina de las islas Malvinas es legítimo porque el Reino Unido realizó una ocupación ilegal. Lo controvertido está en las dudas acerca de si el fundamento de la guerra de 1982 tuvo su origen en una preocupación por la soberanía nacional.

ria y Derechos Humanos. Una de las medidas más radicales (que permitió que se reabrieran los juicios contra los responsables de la represión) fue la declaración de nulidad e inconstitucionalidad de la Ley $\mathrm{n}^{\circ}$ 23.492 de Punto Final y de la Ley n. ${ }^{\circ} 23.521$ de Obediencia Debida promulgadas por el gobierno de Raúl Alfonsín durante 1986 y 1987 respectivamente. Esas leyes, conocidas como las "leyes de impunidad", habían impedido continuar con la acusación penal de las violaciones a los derechos humanos cometidas por las Fuerzas Armadas ya que establecieron la imposibilidad de continuar con los juzgamientos a militares que aún no habían sido acusados afirmando que los delitos cometidos no eran punibles ya que obedecían órdenes de superiores. La nulidad de esas leyes también dio lugar a que algunos jueces declarasen la inconstitucionalidad de los indultos decretados por el ex presidente Carlos Saúl Menem entre 1989 y 1990 que liberaron de todo cargo y culpa a aquellos que habían llegado a ser acusados a través del Juicio a las Juntas (1985). 
Múltiples fuentes ${ }^{9}$ afirman que la guerra fue una “aventura militar” (Rattenbach, 1982: 72) y que la Junta Militar aprovechó ese conflicto histórico para intentar perpetuarse en el poder porque en 1982 tenía un importante descrédito y comenzaban a sucederse manifestaciones populares que reclamaban la restitución del orden democrático. Por lo cual, la posibilidad de ganar la guerra de Malvinas significaba el restablecimiento de la legitimidad del gobierno de facto. Al respecto, el Informe de Ratenbach, ordenado por la misma Junta Militar para el análisis y evaluación de las responsabilidades en el conflicto bélico del Atlántico Sur, expresaba:

El procedimiento adoptado por la Junta Militar para preparar la nación para la guerra contradijo las más elementales normas de planificación vigentes en las Fuerzas Armadas y en el Sistema Nacional de Planeamiento.

Ello motivó a que se cometieran errores fundamentales respecto de la orientación politica y estratégico militar con que se inició el conflicto, y aquella con que se lo concluyó. De no haberse cometido este error, pudo cambiar el curso de la guerra y haberse podido lograr el objetivo politico que se perseguía de otra forma (Rattenbach, 1982: 173).

Así las cosas, en medio de un agitado clima social y con la decisión firme de desatar

\footnotetext{
${ }^{9}$ Informe de Rattenbach (1982), Centro de Ex Soldados Combatientes en Malvinas de Rosario, Federación de Ex Combatientes de la provincia de Santa Fe, Dirección de Comunicación Multimedial de la Universidad de Rosario, Secretaría de Gobierno de la Municipalidad de Rosario, Ministerio de Educación de la provincia de Santa Fe y Centro de Estudiantes de la Facultad de Ciencia Política de Rosario. (Ed.). (2009). Soldados de Ayer, Combatientes de Hoy y Siempre [CD-ROM]. Rosario, Argentina. Solano M. C., Borini M., (1997). La salud antes y después de la guerra. Instituto Nacional de Servicios Sociales para Jubilados y Pensionados (INSSJP), Buenos aires, Argentina.
}

una guerra, la Junta Militar reclutó a los jóvenes del servicio militar obligatorio para llevarlos a las islas hablándoles de la posibilidad de conocer el mar y de una "recuperación". Pero esos jóvenes tenían 18 años, pocos meses de servicio militar y no contaron con el armamento ni con la logística básica para llevar adelante una guerra en el extremo sur. Mientras que Reino Unido, al ser una potencia mundial, contaba con un ejército provisto de lo necesario para combatir y ganar.

El 2 de abril las tropas argentinas desembarcaron en Malvinas y dos meses después el conflicto bélico llegó a su final. En palabras de un ex combatiente:

La indiferencia social posterior al conflicto contrastó con el fervor patriótico que el 2 de abril de 1982 generó el anuncio de la 'recuperación' de las Islas Malvinas, en boca del dictador Leopoldo Galtieri. La Plaza de Mayo de Buenos Aires, teñida de color celeste y blanco, se colmó de miles de ciudadanos, entre ellos muchos reconocidos dirigentes politicos y sindicales. Aclamaban a Galtieri, quien decia: "si quieren venir que vengan, les presentaremos batalla".

Al final de la guerra, el 14 de junio, todo cambió de golpe. Tras la derrota, esa misma gente trató de incendiar la casa de gobierno, echó a Galtieri del poder y no quiso volver a hablar de Malvinas. El final del conflicto cerró el capitulo de la dictadura y fue un factor decisivo para la reinstauración de la democracia, pero en cuanto a la guerra, la sociedad no se bizo cargo de sus responsabilidades.

Las autoridades y la sociedad se comportaban como si los soldados fuesen los responsables de la derrota. Hubo un acuerdo tácito para olvidar la guerra, esconder a los que regresaban y borrar de las mentes lo vivido. Para obtener la baja militar, los oficiales hicieron firmar a los soldados una declaración jurada, en la 
que nos comprometiamos a callar y por ende a olvidar. Hablar de la guerra, de lo ocurrido durante la guerra, fue lo primero que nos probibieron. Asi, el dolor, las bumillaciones, la frustración, el desengaño, la furia, quedaron dentro de cada uno de nosotros hasta tornarse insoportables en muchos casos. Es que hablar, contar, era el primer, necesario paso para exorcizar nuestro infierno interior y empezar a curar las heridas. Pero no se podia, eran cuestiones de Estado. De modo que el regreso fue cruel, en silencio, a escondidas, como si fuésemos un grupo de cobardes. La bienvenida quedó para el hogar (Esteban, 2008, parra $3,4$ y 5$)$.

Como se lee, aquellos que combatieron en Malvinas no sólo carecieron de asistencia o reconocimiento cuando regresaron sino que para poder obtener la baja fueron obligados a esconder el hecho de haber ido a una guerra. Los años posteriores a la guerra las fuerzas militares intentaron silenciar lo ocurrido y la sociedad tampoco interrogó el tema confrontando a los ex combatientes primero con la indiferencia, luego con la estigmatización y la exclusión, fenómeno que suele denominarse "desmalvinizacion". ${ }^{10}$ Además, cabe destacar que la mayoría de los jóvenes reclutados para la guerra provenían de familias muy humildes que no habían podido terminar ni la escuela primaria por vivir en la pobreza (INSSJP, 2008), con lo cual les fue muy difícil costear de manera particular cualquier tipo de tra-

\footnotetext{
${ }^{10}$ Fue Alain Rouquier, politólogo y sociólogo francés, el que parece haber acuñado el término en una entrevista realizada por Osvaldo Soriano para la revista Humor en marzo de 1983 donde afirmó: "Quienes pretendan evitar que los militares vuelvan al poder tienen que dedicarse a desmalvinizar la vida Argentina. Esto es muy importante: desmalvinizar, porque para los militares las Malvinas serán siempre la oportunidad de recordar su existencia, su función, y un dia, de rehabilitarse. Intentarán hacer olvidar la guerra sucia contra la subversión y harán saber que ellos tuvieron una función evidente y manifiesta que es la defensa de la soberanía nacional".
}

tamiento y atravesar la posguerra sin poder conseguir trabajo. Por todo eso, consideramos que aunque 1983 se haya restablecido la democracia continuó para muchos una especie de errancia: aquellos que sufrieron un tipo muy particular de violencia física y simbólica perdieron los elementos con los que alguna vez organizaron su identidad y cargaron con una destrucción que fue muy difícil dejar atrás. Continuaron viviendo sobre esa destrucción, sobreviviendo. Señala Solano (1997), psicóloga, terapeuta e investigadora de la salud de los veteranos de Malvinas, que luego de la guerra muchos padecieron $y / o$ padecen un gran sentimiento de culpa por haber quedado con vida, por no poder hacer algo para resarcir la injusticia de lo ocurrido, recuerdos constantes de situaciones relacionadas con la forma en que se murieron compañeros y con momentos de soledad donde la vida se vio fuertemente amenazada o agraviada. Además, es importante señalar que lo más gravoso para muchos fue el hecho de haber tenido que esconder durante los años posteriores a la guerra su condición de ex combatiente de Malvinas. Si tomamos en cuenta que el asunto principal del ser humano es ser reconocido por lo social en su singularidad ${ }^{11}$, su nombre propio y su recorrido vital es lógico que para algunos veteranos haber sido obligados a esconder parte de su historia significó una especie de exilio en su propia tierra.

\footnotetext{
${ }^{11}$ Bruno Bettelheim (1981) afirma que en el campo de concentración nazi el problema principal era el de conseguir afirmarse en algo que permita sostener, lo que llama "la autoestima". El punto era "salvaguardar su ego de tal manera que, si su buena suerte le hacía recobrar la libertad, fuese aproximadamente la misma persona que era en el momento de verse privado de ella" (p. 85). El asunto principal estaba entonces en la posibilidad de conservar algo de lo que había sido antes de pasar esa experiencia. Y por otro lado, también señala que era crucial el hecho de sentir que a otros les importaba. Al respecto escribe: "La peor de las agonías es la de sentirse absolutamente abandonado" (Bettelheim, 1981: 12).
} 
Es un dato alarmante que desde el final de la guerra se hayan suicidado alrededor de 800 ex soldados combatientes, más de los 649 que murieron durante el conflicto bélico. $\mathrm{Y}$ es también llamativo que el sufrimiento de muchos veteranos suele enmarcarse dentro de las variables del "Trastorno por estrés postraumático"12, sin mencionar los efectos que pueden acarrear determinada forma de uso y abuso del poder estatal, es decir, de convertir a un grupo de jóvenes en "guerreros por la patria" para luego obligarlos a esconderse en sus casas. A nuestro criterio, a la hora de pensar abordajes posibles poner el eje en la guerra en sí y en el enfoque de los trastornos y patologías, lejos de reparar, refuerza cierta patologización que ha padecido el grupo. Es fundamental incluir las vivencias de los veteranos de Malvinas en los procesos históricos y sociales de la Argentina porque si no, en la medida que se individualiza el sufrimiento, se corre el riesgo de soslayar los efectos que generaron en los veteranos las interpretaciones y elaboraciones sociales respecto a la guerra de Malvinas y al pasado reciente.

Actualmente se encuentran en mejores condiciones económicas porque después de una larga lucha los ex combatientes organizados consiguieron ser reconocidos a nivel estatal como Veteranos de Guerra, a través de pensiones provinciales y nacionales (recién a partir de la década del '90). Pero el dinero sólo no sirve de reparación. Muchos continúan

\footnotetext{
${ }^{12}$ Es un diagnóstico que proviene del Manual Diagnóstico y Estadístico de los Trastornos Mentales o DSM que refiere a reacciones ocasionadas por situaciones estresantes entre las que se encuentra el becho de participar o combatir en una guerra. 'En 1980 se acuñó oficialmente, en la terminología psiquiátrica, la denominación de Trastorno por Estrés Postraumático (TEPT) en la tercera versión de la clasificación diagnóstica de la Asociación Psiquiátrica Americana (DSMIII). Desde esa fecha en adelante este cuadro clínico ha cobrado gran importancia hasta alcanzar su máxima divulgación con ocasión de los ataques terroristas del 11 de septiembre de 2001 a las Torres Gemelas del WorldTrade Center de Nueva York y al Pentágono en Washington" (Carvajal, 2002: parr. 1).
}

con serios problemas a causa del delicado lugar que ocupa la guerra de Malvinas en nuestra historia ${ }^{13}$ (Solano, 1997; INSSJP, 2008). Al parecer, a nivel social las discusiones alrededor de Malvinas están más atrasadas respecto de los debates sobre el terrorismo de Estado y la militancia política previa (Lorenz, 2007).

Los planteos de Feierstein (2012) ya citados también permiten pensar parte de las problemáticas mencionadas. El ejercicio del terror que destruyó relaciones sociales de autonomía y cooperación también afectó al grupo que le tocó ir a Malvinas. De lo contrario, ¿cómo se explica que las miles de personas que alentaron a los jóvenes a ir a la guerra no dijeron absolutamente nada a sus regresos? ¿Por qué los veteranos repiten que en vez de un reconocimiento social hubo estigmatización y exclusión? ¿Por qué se los obligó a guardar silencio sobre todo lo ocurrido en las islas para poder obtener la baja? ¿Por qué el mismo informe de Rattenbach habla de “aventura militar"? ¿Por qué hubo tanta cantidad de suicidios?

Desmalvinización fue un modo de nombrar el silencio y la destrucción de relaciones de cooperación que alguna vez estuvieron y que, por lo tanto, esperaban en el regreso. Al respecto señala Feierstein:

\section{Las prácticas sociales genocidas no culminan con su realización material (el aniquilamiento material de una serie de fracciones amenazan- tes y construidas como "otredad negativa"),}

\footnotetext{
${ }^{13} \mathrm{Al}$ respecto Segade (2016) señala una cuestión muy importante: “(...) la reparación económica de los noventa no se apoya en una reparación legal previa. En ese sentido, la nueva situación -la "reconciliación" entre poder político y militar y el hecho de que, como consecuencia, en los relatos estatales sobre la guerra, los militares ocupen lugares cada vez más destacados- no redundó en un auge ni en una reconfiguración de las narrativas testimoniales de la guerra, ni tampoco brindó a los soldados la posibilidad de elaborar narrativamente sus experiencias" (p. 14).
} 
si no que se realizan en el ámbito simbólico e ideológico, en los modos de representar y narrar dicha experiencia traumática (Feierstein, 2012: 180).

Es decir, el objetivo último del genocidio es que no quede rastro del exterminio, que no reaparezca lo que desapareció. Lo cual nos permite pensar por qué durante largo tiempo se quiso eliminar la historia de la guerra de Malvinas, estigmatizando y patologizando a aquellos que necesitaban hablar de lo ocurrido, tanto de lo doloroso como de lo positivo, es decir, de su experiencia personal. "Loco de la guerra" fue una representación que borró las huellas de lo que desapareció. La sociedad no pudo, no quiso o no tuvo material disponible para ponerse a pensar qué había pasado con los jóvenes que volvieron de la guerra y con los que ya no estaban: "los ex combatientes estaban mal porque estaban locos" y ahí, casi por veinte años, se cerró la cuestión. Pero como contracara del silencio y la estigmatización, los ex soldados se agruparon y formaron un colectivo para defender sus derechos, desafiando con ese mismo gesto al genocidio, embanderando justamente aquello que la dictadura se propuso eliminar: la historia de los soldados ex combatientes, la auto organización y la cooperación. Nótese que los Centros de Ex Combatientes establecen que su primera función es "conservar en la memoria a los compañeros caídos en combate”. Así, los mismos sobrevivientes agrupados fueron los primeros que convirtieron a los muertos de la guerra en "compañeros caídos en combate", inscribiendo sus nombres. Esto probablemente significó una de las vías colectivas para elaborar parte del horror esa experiencia.

Luis Gusmán (2005) ubica el derecho a la muerte escrita mientras trabaja la relación entre el epitafio como género fúnebre y la problemática de la identidad. El autor retoma la historia griega para subrayar lo que él llama derecho a la muerte escrita en los principios que sostienen la fundación de la Polis (Gusmán, 2005: 339).
Describe que la peor ofensa que podía recibir un ciudadano después de muerto era la abolición del apellido, de los funerales y el sepulcro. Entonces el derecho a la muerte escrita establecía que un ciudadano debía tener una placa donde figuraran los datos de filiación y el lugar donde había fallecido. Lamentablemente, dice Gusmán, con el tiempo ese derecho se reservó sólo a los ricos, y los pobres tuvieron que conformarse con fosas comunes (p. 339).

Pensando la guerra de Malvinas a la luz de estas últimas elucidaciones y retomando lo esbozado más arriba acerca de la auto organización del grupo que participó en la guerra, podemos ubicar que ante la imposibilidad del ritual de la sepultura que implica toda guerra, el grupo de ex combatientes de Malvinas al crear sus propias instituciones fundó rituales que oficiaron de simbolizaciones de las muertes, y redujeron así la destrucción que la cuestión pudiera seguir ocasionando, abrieron la posibilidad de transmisión de la historia, convirtieron en un problema social un dolor que había quedado en el orden de lo particular. El derecho a la muerte escrita es una exigencia que permite la reintroducción de lo humano y la transmisión hacia otras generaciones.

\section{Transmisión, memoria, identidad.}

Desde el sentido común, es posible pensar que el término transmisión alude al proceso por el cual se pasa o se comunica algo de un punto al otro o, para el caso, de una persona a la otra. Toda sociedad se sostiene en y a través de diversos procesos de transmisión: unos hombres pasan a los que le siguen costumbres, hábitos, ideas, valores, experiencias del pasado que permiten procesos de identificación, de filiación a una historia y a una genealogía.

Puesto que, en resumidas cuentas, la transmisión constituiría ese tesoro que cada uno se fabrica a partir de elementos brindados por los padres, por el entorno, y que, remodelado 
por encuentros azarosos y por acontecimientos que pasaron desapercibidos, se articulan a lo largo de los años con la existencia cotidiana para desempeñar su función principal: ser fundante del sujeto y para el sujeto (Hassoun, 1997: 121).

Hassoun(1997) trabaja el concepto de inscripción en tanto operación que permite situarse en una genealogía, en una filiación, y que se propicia cuando es posible una transmisión intergeneracional que da lugar a una construcción singular. Así es que remarca que no hay que entender la filiación sólo en el sentido de la pertenencia sino que “es más hacia la diferenciación que hacia la especificidad que se dirige la transmisión (...). Aquello que permite aprender lo que me diferencia de aquellos que poseen una historia similar a la de los míos" (Hassoun, 1997: 150). La transmisión se acerca más a un "discurso procesado de contrabando, clandestinamente de lo que se ofrece como herencia” (p.148).

Porque si la repetición inerte implica con frecuencia una narración sin ficción, la transmisión re introduce la ficción y permite que cada uno, en cada generación, partiendo del texto inaugural, se autorice a introducir las variaciones que le permitirán reconocer que lo que ba recibido como herencia, no es un depósito sagrado e inalienable, sino una melodía que le es propia. Apropiarse de una narración para hacer de ella un nuevo relato, es tal vez el recorrido que todos estamos convocados a efectuar. Las palabras a lo mejor son siempre las mismas pero existe un estilo que es particular a ese grupo, a esa familia, a tal o cual, que permitirá que cada uno retome por su cuenta la fórmula de Goethe: "lo que has heredado de tus padres, conquístalo para poseerlo" (Hassoun, 1997: 178, 179).

Pero Hassoun advierte que además de transmisiones logradas puede haber quiebres, cortes, rupturas en los procesos de transmisión de una generación a la siguiente. Es decir, interrupciones que generan sufrimientos específicos. Y además ubica que son ciertos contextos los que propician esos cortes: en Europa fueron ideologías de la exclusión las que, en nombre de supuestas fidelidades, reenviaron a sectores minoritarios a la extranjereidad, excluyéndolos de la historia nacional y obligándolos a silenciar partes de sus historias (Hassoun, 1997). A partir de algunos casos clínicos, el autor llega a decir que para los hijos de aquellas personas que fueron rechazadas por la comunidad habiéndose identificado totalmente con su país, la referencia a la transmisión será una necesidad que comprometerá la verdad del sujeto.

Otro planteo interesante al respecto es el de Marcelo Viñar (2008), psicoanalista uruguayo, quien analiza el impacto del terror en la trasmisión entre generaciones planteando que la violencia política extrema implicó entre otras cosas la destrucción de la constelación identificatoria que constituyó la singularidad de miles de sujetos para convertirlos en "desechos de sí mismos” (Viñar, 2008: 134) y un consecuente proceso de estigmatización lo cual ha generado múltiples traumatismos psíquicos. Dice el autor:

Nuestra tesis es que esta perturbación del legado transgeneracional en la psicología de los pueblos, en la psicología colectiva, tan decisivo en la estructuración psíquica y en la construcción identitaria, es en la actualidad una pandemia que merece mayor investigación. Cuando la transmisión de confianza inberente a la familia humana se canceriza en el oprobio y en el rencor las consecuencias son a largo plazo y llegan a la tercera generación. Pandemia que no solo por su número "bay millones de afectados" sino por la cualidad y el alcance de sus efectos tendrá consecuencias en la descendencia; la clínica analítica es elocuente respeto de ello. (Viñar, 2008: 136) 
Los diferentes modos de trabajar los duelos, las pérdidas y las representaciones sobre el pasado que cada generación se forja influyen en la siguiente. Con lo cual se torna necesario intentar dilucidar, a sabiendas de que es un proceso altamente singular, cuales son las vías (o si es que hay) que colaboran en posibles elaboraciones de los sucesos históricos mencionados.

Desde el marco teórico de la sociología también existen estudios interesantes para pensar el tema pero desde la perspectiva de grupo. Es, entre otros, Maurice Halbwachs (2004) quien habla del concepto de grupo para analizar la memoria colectiva y la transmisión. El autor plantea que toda sociedad funciona como marco donde persisten los recuerdos y las imágenes de un pasado que se recrea con parte del presente pero que cada grupo tiene su memoria y la transformación de esta actúa sobre la vida y el pensamiento de sus integrantes. Las diferentes memorias colectivas mantienen por algún tiempo el recuerdo de acontecimientos que sólo tiene importancia para ellas mismas (Halbwachs, 2004: 212). Habría infinitas memorias colectivas ligadas a imágenes y sentimientos pero todas tienen como soporte un grupo limitado en el espacio y en el tiempo.

Remarca el autor que la memoria colectiva retiene del pasado sólo lo que aún está vivo o es capaz de vivir en la conciencia del grupo que la mantiene (Halbwachs, 2004: 214) y advierte que la reconstrucción de los recuerdos de un grupo sólo puede hacerse junto a otros:

Para que la memoria de los otros venga asi a reforzar y completar la nuestra también hace falta, decíamos, que los recuerdos de esos grupos estén en relación con los hechos que constituyen mi pasado. Cada uno de nosotros, en efecto, es miembro a la vez de varios grupos más o menos grandes (Halbwachs, 2004: 211).
Así planteada, la memoria puede pensarse como exigencia de trabajo, como proceso de construcción que permite tomar algo del pasado para ubicarse en el presente y proyectarse. La identidad es el resultado de la multiplicidad de historias que un sujeto construye sobre sí mismo, sobre la historia de su vida ${ }^{14}$. En cierta medida somos las historias que contamos, los recuerdos que construimos y nos colocan en una particular relación con nuestro presente y con nuestro futuro. En este sentido Feierstein (2012) también hace un vasto análisis de diferentes disciplinas que han investigado el tema de la memoria arribando a la conclusión de que el recuerdo es una reconstrucción, no una reproducción y que la memoria es principalmente creadora, constructora. Además, se genera en cada acto de renovación y no de una vez y para siempre y tiene una estrecha relación con el presente en tanto genera determinada acción y no otra.
Construir un recuerdo implica simultánea- mente construir identidad, en tanto se constru- ye un sujeto consciente que se relaciona con di- chos elementos dispersos de pasado y construye de ese modo una escena, un presente recordado en el cual surge una narración de sí mismo. Pero esta narración de si mismo no surge solo de las propias percepciones y representaciones si no que cada uno lleva en sí mismo tanto a sus predecesores como a sus contemporáneos, asi como una visión de sus sucesores (Feiers- tein, 2012: 59).

Para profundizar el análisis de los procesos de memoria y la construcción de identidad, Feierstein (2012) retoma algunos teó-

\footnotetext{
${ }^{14}$ Esta definición fue trabajada por el psicólogo Iván Fina en su charla sobre "Genocidio, filiación y transmisión" cuando se refería al concepto de Identidad Narrativa acuñado por Paul Ricoeur. La charla fue organizadas por la comisión de formación de Salud Mental de la Municipalidad de Rosario, Hospital Carrasco, en marzo de 2015.
} 
ricos que establecen que la doble condición para generar una memoria a largo plazo es la repetición y la afección emocional y que la mayoría de los sucesos de gran afección emocional quedan registrados sólo a nivel inconsciente. Gran parte de la memoria a largo plazo pasa a nivel consciente pero en los casos en que la emoción puede afectar a la constitución identitaria esos recuerdos quedan restringidos por el mecanismo de represión, lo cual resulta relevante para dimensionar hasta qué punto ciertos recuerdos y afectos, cierta parte de la identidad de una generación, pudo haber quedado congelada por los efectos del terror.

Este quiebre de lazo social opera de varias maneras, pero una de las más demoledoras la constituye la cosificación de la generación que vivió el genocidio como "primera y unica”, proceso que convierte a las generaciones siguientes en huérfanas en todo sentido, sea porque se le hace cargar con muertes que no terminan de comprender, sea porque confrontan con una generación que no alcanza a reconstruir un sentido coherente en la transmisión de su propia experiencia, oscilando entre una "idealización" inalcanzable de los héroes asesinados y una renegación de las utopias alguna vez defendidas, modos polares e irreconciliables pero que sin embargo, clausuran por igual la posibilidad de generar un legado transgeneracional, la propia posibilidad de transmisión (Feierstein, 2012: 162).

El grupo de sobrevivientes de Malvinas y su grupo familiar afectados directa e indirectamente vivieron los años posteriores a la guerra en una gran soledad. En la medida en que no había nadie dispuesto a escuchar o registrar lo que pasaba se hizo muy difícil articular la historia privada a la historia social, narrar una experiencia. Los únicos testigos de todo eso fueron los del ámbito familiar. Es muy probable que muchos hijos también sufrieran la exclusión y la estigmatización de sus padres porque vivieron en carne propia esa paradoja por la cual aquellos que habían ofrendado su vida a la patria eran mirados por la sociedad como los "locos de la guerra".

\section{Otra época, otra épica: la palabra de los bijos.}

Llegados a este punto, habiendo situado algunos de los problemas que enfrenta parte de la generación sobreviviente, nos preguntamos por los descendientes. Los '80 y los ' 90 fueron años en los que se visibilizaron las transformaciones económicas y sociales generadas por las políticas del mencionado modelo neoliberal que la dictadura logró profundizar: acrecentamiento de la pobreza y la marginación, enriquecimiento ilícito de diferentes grupos económicos, privatización de lo público, precarización laboral y fragmentación de toda una trama social. En ese contexto nacieron y crecieron jóvenes que también se enfrentaron con un importante trabajo de reconstrucción y construcción.

Si tenemos en cuenta que la narración de las historias de cada identidad se construye en parte a través de los demás, nos preguntamos: ¿Qué ocurre cuando los antecesores han silenciado partes cruciales de sus vidas o no pueden salir de la repetición? ¿Qué significa ser joven después de que miles de jóvenes murieron de los modos más cruentos posibles?

Freud (1908) sostiene que todo ser humano en su desarrollo para llegar a ser adulto requiere dejar atrás a los padres, cuestionarlos y separarse. Pero, ¿cómo ha de resolver esta operación alguien cuyo padre sobrevivió a una guerra y además quedó en lugar de héroe que no ha tenido el debido reconocimiento? ¿Cómo rebelarse contra rebeldes que han sufrido muerte de amigos, guerra, torturas, persecución, etc.? ¿Cómo dejar de venerarlos y respetarlos? ¿Cómo romper con la sacralidad desde la cual no es posible preguntar nada 
nuevo $?^{15}$

En un mundo de trashumancia, según Hassoun (1997), todos somos contrabandistas de lo que desaparece y emerge, el punto está en inventar nuevas formas de transmisión: "De transformar lo que podría ser un cementerio en un área lúdica. Jugar con la lengua. Usar y abusar de ella sin temor" (p. 64).

Después de 1982, en medio de una gran conmoción y en un clima social de negación a muchos padres les fue imposible ubicar qué sucedía o qué sucedió. Luego de muchos años y a partir de algunos procesos sociales es que algunos pueden comenzar a preguntar y otros a historizar y en ello situamos una vía de elaboración intergeneracional. Frente a catástrofes de la magnitud de la que estamos hablando quizás las elaboraciones no sean ni de una generación, ni de otra, sino en un lugar intergeneracional.

En las entrevistas los hijos ubicaron una tensión siempre presente, dos interpretacio-

\footnotetext{
${ }^{15}$ Elsa Drucaroff (2011), analizando el ámbito de la literatura (la llamada NNA: "nueva narrativa argentina"), describe a la generación pos dictadura como a la intemperie, cuyos antecesores quedaron con dificultades para trasmitir que el presente que se vive tiene un porqué. Advierte sobre el hecho de que ' $\mathrm{La}$ dictadura militar que se inicia en 1976 se vive como limite en el imaginario histórico de las nuevas generaciones" (p. 27) en la medida en que parece que el mundo comenzara desde allí y no aparece nada de lo que pasó antes. Esto plantea algunos problemas cruciales: "El primero es cómo ser rebelde cuando los más viejos se atribuyen toda la rebeldía posible. ¿Cómo desobedecen los hijos el mandato paterno "sé rebelde", un mandato que inmoviliza y oprime? Este mandato y esta opresión se leen hoy en filigrana en las obras de la NNA, construyen situaciones explícitas o connotadas de filicidio, una mancha temática que recorre, como veremos, la narrativa de posdictadura. (...) El segundo problema es (suponiendo que se superara esta inmovilidad) la culpa, ¿qué sería rebelarse contra rebeldes que además han sufrido persecución, tortura, muerte de amigos, hijos, hermanos, novios y son además tan prestigiosos y respetados en el campo intelectual y la academia, ambos con hegemonía oficial democrática y progresista?” (p. 53).
}

nes contrarias acerca del mismo hecho que coexisten: la guerra aparece como una gesta histórica y como un hecho sin sentido en medio de un pasado trágico, donde las cosas se hicieron mal y de improvisado. En esa versión los padres se representan siendo enviados a una guerra sin haber sido avisados, padeciendo maltratos y a su vez participando activamente de un hecho heroico, defendiendo la patria. También ubican que cuando los veteranos están mal por la cuestión Malvinas eso tiene relación con los compañeros fallecidos en la guerra pero sobre todo con los suicidios, es decir, con los fallecidos en Argentina o con aquellos que no pudieron rehacer sus vidas $y$ se encuentran muy mal ahora. También con el no reconocimiento y la estigmatización que sufrió el grupo. Todos afirman que en la década del '90 sufrieron la "desmalvinizacion", el hecho de soportar el desprecio social, que los padres fueran mal vistos y que eso fue muy difícil para toda la familia. Se figura al Ex Combatiente como la cara visible de un proceso que durante los ' 90 todo el grupo familiar vivió en soledad.

Durante muchos años los padres no hablaron acerca de lo que pasó en la guerra ni sobre lo que pasó después y los hijos tampoco pudieron preguntar. Sólo les fueron contadas algunas anécdotas a partir de cosas puntuales que fueron pasando, sobre todo cuando el padre hablaba con otros ex combatientes, con amigos o cuando acontecía algo en relación a Malvinas. Con esto se corrobora que la memoria del pasado se arma a partir de otros (Halbwachs, 1994), que después de determinado tipo de experiencias si no hay encuentro con quienes hayan sido parte de ese pasado, no hay reconstrucción del recuerdo, ni relato, ni posibilidad de transmitir ciertas memorias a los demás. Pero a su vez, los hijos señalan que es un tema muy delicado para preguntar, que existe cierta dificultad para poder interrogar el tema y una sensación de que hacen mal si cuestionan algo porque reenvían a los padres 
a sensaciones de tristeza y malestar. Todo ello hace pensar en lo difícil que fue y que es construir una versión del pasado que no esté tan marcada por el afecto de la angustia o el dolor.

El hecho de que el grupo de veteranos haya vivido muchos años con la amenaza de no poder hablar por el papel que tuvieron que firmar para poder obtener la baja del servicio militar probablemente fue algo crucial para determinadas rupturas en la transmisión. Todos ubican que eso fue algo muy difícil para sus padres y los entrevistados más grandes dicen que fue muy difícil para ellos también porque por momentos vieron a un padre triste, atemorizado, imposibilitado de trabajar, etc., sin entender bien porqué. Vemos cómo el conjunto de factores configuró una modalidad de sufrimiento ligada a no entender el porqué.

Los hijos también dicen que no pudieron hablar mucho de la cuestión Malvinas con otras personas, que es recién luego del 2003 que la gente se interesa, pregunta o quiere escuchar y que eso les permite a ellos hablar y a su vez preguntar. "La sociedad" aparece indiferente en algunos relatos y en otros con cierto interés ligado a lo fantástico de la guerra, a las historias insólitas pero, repiten, que fue, sobre todo, en el último tiempo.

Por otro lado, aparece una diferencia entre los más grandes y los más chicos. Los últimos no trasmiten el mismo registro de un 'padre dolido` que los primeros porque no convivieron con su padre en la etapa más difícil. Con lo cual vemos la recomposición que significó a nivel familiar el hecho de que el Estado haya reconocido y por lo tanto incluido a los veteranos de guerra en cierta historia oficial. De todos modos, también aparece la idea de que con la pensiones otorgadas por el Estado a partir del reconocimiento como Veteranos de la guerra de Malvinas no se saldó una deuda simbólica que se tiene con el grupo.

Surgen preguntas de los hijos acerca de cómo la sociedad va a recordar al grupo cuan- do los veteranos ya no estén, qué deberían hacer ellos para que no se olvide el problema de la soberanía Argentina y lo que pasó con la guerra de Malvinas. Algunos de esos interrogantes ¿acaso no expresan cierta preocupación por la memoria de los caídos en y después de la guerra que son para quienes, en principio, se creó la agrupación? Quizás de alguna forma se transmitió aquello que no tiene elaboración: las muertes injustas, los suicidios que podrían haberse evitado. $\mathrm{Y}$ en esto podríamos decir que hay cosas de la cultura que no admiten desaparición. Por algo el derecho a la muerte escrita (Gusmán, 2005), por algo la necesidad del reconocimiento de lo ocurrido en lo social, por algo aún hoy hay cosas que los hijos no dejan de nombrar.

Por último, los hijos también hablan del fuerte registro que tienen de la lucha que emprendieron los padres para conseguir el reconocimiento de sus derechos y de la actual promoción de acciones solidarias que realizan. En este sentido podríamos decir que los veteranos y sus hijos, instituyendo una comunidad que pregona la solidaridad, desafiaron al genocidio. Porque en cierto sentido embanderan justamente aquello que las prácticas genocidas quisieron desarmar: ese modo de lazo social. En todos los relatos aparece la idea de que la solidaridad es lo que el padre predominantemente trasmitió.

\section{A modo de conclusión}

Consideramos que para posibilitar algo del orden de una transmisión es necesario que la generación sobreviviente pueda aliviar su padecimiento, hacer sus duelos, significar lo que pasó. Para lo cual es preciso que sea reconocida como tal, que tenga un lugar físico y simbólico donde poder articular su historia singular con la historia social, tanto para poder narrar lo que fue indignidad como para poder valorizar una experiencia que no pudo rescatar. Es necesario que ese reconocimiento 
sea propiciado desde ciertos lugares estatales ya que abordamos sucesos que fueron generados por el mismo Estado o por grupos que se apropiaron del mismo (Viñar, 2007). Hay cierta reparación que solo puede darse en la medida en que el Estado (las personas e instituciones que lo representan) encuentren formas de reconocer las diferentes experiencias y terminar con la prohibición de hablar, de contar, de narrar. Afirma Viñar (2007) que para propiciar elaboraciones del tipo de sucesos de los que hablamos, en los que están en juego muertes que no han tenido inscripción social, es necesaria la institución del tercero social porque es lo que abre la posibilidad de hacer un duelo y resignificar las pérdidas. Estas operaciones son las que van permitiendo destrabar formas de sufrimiento enquistadas, curar parte de las heridas de una violencia pasada y hacer lugar a otros afectos, a otros recuerdos, a que una generación hable y otra pregunte $y$, así, exista la posibilidad de una herencia, de una memoria que sirva para desmontar injusticias aún presentes.

Hablamos de conflictos subjetivos que requieren de condiciones sociales favorables que auspician como resarcimiento a una generación (a los padres) y que posibilitan a la siguiente generación (los hijos) una elaboración de las marcas heredadas (Freud, 1913), es decir, una tramitación de la destrucción que habilita un porvenir que no esté signado por la repetición (Freud, 1937).

Las interpretaciones que niegan el hecho de que la dictadura cívica militar ejerció una violencia sistemática con toda la sociedad, incluyendo el acto de desatar una guerra sin tener los recursos para hacerlo, no dejan lugar para poder contar, situar, historizar muchas experiencias. Obligan a ciertos afectos, a determinados recuerdos a abandonar su lugar, su suelo. Los instan a un exilio interno, dejándolos sin relato, sin palabras, sin posibilidad de movimiento. Lo que pasó en la guerra de Malvinas y después de Malvinas no fue lo que pasa después de cualquier guerra, fue lo que pasó después de una guerra que se desató en el marco de la más cruenta de las dictaduras argentinas. Ello no implica que todos aquellos que eran militares de carrera durante la guerra sean responsables de los atropellos cometidos. Muchos desconocían lo que ocurría y se habían alistado al ejército con la convicción de servir al pueblo argentino (hay numerosos testimonios de soldados que hablan muy bien del trato y el desempeño de sus oficiales). Y sobre todo, ubicar que aún en medio de la hostilidad y careciendo de lo básico para combatir los soldados y la tropa argentina tuvieron un desempeño ejemplar y dejaron o arriesgaron su vida por la patria, en nombre de nuestra soberanía. Es necesario construir interpretaciones que puedan hacer lugar a esta complejidad, a tensiones que no admiten síntesis.

Para terminar nos preguntamos ¿de qué otras formas a nivel social se pueden propiciar elaboraciones intergeneracionales, es decir, inscripciones que desarmen significados coagulados en formas de sufrimiento enquistadas y hagan lugar a sentidos nuevos pero filiados a la trama social? Porque si no se ponen palabras, algunos silencios van a seguir insistiendo camuflados en el mismo texto; en una memoria sin ficción, sin variación, sin movimiento. En la narración de una tragedia que se quiere olvidar y que a la vez no se puede dejar atrás; en la transmisión de estar olvidado entre la dictadura y la democracia, como un relato perdido en el mar.

\section{Referencias:}

- AMERICAN PSYCHIATRIC ASSOCIATION.(2000). Diagnostic and Statistical Manual of Mental Disorders. 4th ed Text Revision (DSM-IV-TR). Washington,DC. American Psychiatric Press.

- BETTELHEIM B. (1981). Sobrevivir, el holocausto, una generación después. Barcelona, 
España, Col. Critica, Grupo editorial Grijalbo.

- CALISTO G. (2012). Soldados argentinos estaqueados en Malvinas. Revista Crónica. Recuperado de : http://www.cronica.com. ar/diario/2012/ 08/ 21 /31887-soldados-argentinos-estueados-en-malvinas. html

- CARVAJAL, C. (2002). Trastorno por estrés postraumático: aspectos clínicos. Revista chilena de neuro-psiquiatría, v.40 supl.2, Santiago, Chile.

- CENTRO DE EX SOLDADOS COMBATIENTES EN MALVINAS DE ROSARIO, FEDERACIÓN DE EX COMBATIENTES DE LA PROVINCIA DE SANTA FE, DIRECCIÓN DE COMUNICACIÓN MULTIMEDIAL DE LA UNIVERSIDAD DE ROSARIO, SECRETARÍA DE GOBIERNO DE LA MUNICIPALIDAD DE ROSARIO, MINISTERIO DE EDUCACIÓN DE LA PROVINCIA DE SANTA FE Y CENTRO DE ESTUDIANTES DE LA FACULTAD DE CIENCIA POLÍTICA DE ROSARIO. (ED.). (2009). Soldados de Ayer, Combatientes de Hoy y Siempre [CD-ROM]. Rosario, Argentina.

- CENTRO DE EX SOLDADOS COMBATIENTES EN MALVINAS DE CORRIENTES. (S,F) .La guerra y consecuencias sobre los argentinos que combatieron en Malvinas. Recuperado de: http://www.cescem.o rg.ar/excomb atientes/c onsecuencias. html

- DRUCAROFF, E. (2011). Los prisioneros de la Torre. Política relatos y jóvenes en la postdictadura. Buenos Aires, Argentina, Emecé.

- ESTEBAN, E. (2008). Malvinas, una herida abierta. Buenos Aires, Argentina, Le Monde diplomatique, edición Cono Sur.

- FEIERSTEIN, D. (2012). Memorias y representaciones. Sobre la elaboración del genocidio. Buenos Aires, Argentina, Fondo de Cultura Económica.
- FLORES, C. (2010). El legado de Néstor Kirchner para la política de derechos bumanos. Visión desde el Sur. Recuperado de http:// www.visiondes deelsur.com.ar/ index. php/el-pais / 237-los-legados-de-nestor-kirchner-verd ad-justicia-y-reparacion-social.

- FREUD, S. (2004) (1930[1930]). El malestar en la Cultura. Tomo XXI, Obras completas, Buenos Aires, Argentina, Amorrortu.

- FREUD, S. (1995) (1913 [1912]). Tótem y tabú, tomo XIII, Obras completas, Buenos Aires, Argentina, Amorrortu editores.

- FREUD, S. (1995) [1920]. Mas allá del principio de placer. Tomo XVIII, Obras completas, Buenos Aires, Argentina, Amorrortu.

- FREUD, S. (2003) (1909[1908]). La novela familiar de los neuróticos. Tomo XVI Obras Completas, Buenos Aires, Argentina, Amorrortu.

- FREUD, S. (2003) [1937]. Construcciones en el análisis. Tomo XXIII. Obras Completas, Buenos Aires, Argentina, Amorrortu.

- FREUD, S. (2003) [1914]. Recordar, repetir y reelaborar (Nuevos consejos sobre la técnica del Psicoanálisis, II) Tomo XII, Obras Completas, Buenos Aires, Argentina., Amorrortu.

- FREUD S. (2003) (1917 [1915]). Duelo y melancolía, tomo XIV, Obras completas, Buenos Aires, Argentina, Amorrortu editores.

- GUSMÁN L. (2005). Epitafios, el derecho a la muerte escrita. Buenos aires, Argentina, Grupo Editorial Norma.

- HASSOUN, J. (1997). Los contrabandistas de la memoria, Buenos Aires, Argentina, Ediciones de la Flor.

- INSTITUTO NACIONAL DE SERVICIOS SOCIALES PARA JUBILADOS Y PENSIONADOS (INSSJP), CONSEJO NACIONAL DE INVESTIGACIONES CIENTÍFICAS Y TÉCNICAS (CONICET). (2008). Relevamiento Socio-sanitario de Veteranos de Guerra en las provincias de Chaco 
y Corrientes. Recuperado de http://www. cesce m.org.ar/ xcombat ientes / relev amiento.html

- KLEIN, N. (2008). La doctrina del shock. El ange del capitalismo del desastre. Buenos aires, Argentina, Paidós.

- LEWKOWICZ, IGNACIO. (2008). Pensar sin estado. La subjetividad en la era de la fluidez: Buenos aires, Argentina $1^{\mathrm{a}}$ ed. $3^{\mathrm{a}}$ reimp. Ed. Paidós.

- "Los indultos fueron una violación de las obligaciones” (2004). Página 12. Recuperado de http://www.pagina12.com.ar/diario/ elpais/1-33087-2004-03-21.html

- LORENZ, F. (2007). Entrevista realizada por la revista digital A filo de la Facultad de Filosofía y Humanidades, Universidad Nacional de Córdoba. Recuperado de: http:/ / www.ffyh. unc.edu.ar.

- MiNisterio DE EDUCACIÓN DE LA NACIÓN ARGENTINA. (2014). Pensar Malvinas: Una selección de fuentes documentales, testimoniales, ficcionales y fotográficas para trabajar en el aula. Buenos Aires, Argentina.

- MiNisterio DE EDUCACiÓN DE LA NACIÓN ARGENTINA. (2010). Pensar la Dictadura: Terrorismo de Estado en la Argentina. Buenos Aires, Argentina.
- RATTENBACH B., SÁNCHEZ DE BUSTAMANTE T. A., VAGO A. P., BOFFI J. A., REY C. A., CABRERA F. (1982). Informe de Rattenbach. Buenos Aires, Argentina.

- SEGADE L. (2016). El lugar de la guerra. Relatos de Malvinas en la cultura argentina (1982-2012). Buenos Aires, Argentina. Ed. CLACSO.

- SOLANOM.C. (2010). Otromuertoporabandono, Rosario 12. Recuperado de: https:// www.pagina12.com.ar/diario/suplementos/rosario/14-24012-2010-06-15.html

- SOLANO M. C., BORINI M., (1997). La salud antes y después de la guerra. Instituto Nacional de Servicios Sociales para Jubilados y Pensionados (INSSJP), Buenos Aires, Argentina.

- VIÑAR, M. (2008). "Violencia política extrema y transmisión intergeneracional" en Leticia Glocer Fiorini (comp.) Los laberintos de la violencia. Buenos Aires, Argentina, Editorial Lugar.

- VIÑAR, M. (2007). Diálogo con Marcelo Vinar. Sobre la memoria, la violencia y la educación. Revista el Cardo. Recuperado de: https:// revistaelc ardo.blogia.com/2007/022106di-logo-con-marcelo-vi-ar--sobre-la-memoria-la-violencia...-y-la-educaci-n..php. 